\title{
A simple one-step electrochemical deposition of bioinspired nanocomposite for the non-enzymatic detection of dopamine
}

Vijayaraj Kathiresan ${ }^{1 \dagger}$, Dinakaran Thirumalai ${ }^{2+}$, Thenmozhi Rajarathinam ${ }^{2}$, Miri Yeom², Jaewon Lee ${ }^{3}$, Suhkmann $\mathrm{Kim}^{4}$, Jang-Hee Yoon ${ }^{5^{*}}$ and Seung-Cheol Chang ${ }^{2^{*}}$ (D)

\begin{abstract}
A simple and cost-effective electrochemical synthesis of carbon-based nanomaterials for electrochemical biosensor is of great challenge these days. Our study describes a single-step electrochemical deposition strategy to prepare a nanocomposite of electrochemically reduced graphene oxide (ErGO), multi-walled carbon nanotubes (MWCNTs), and polypyrrole (PPy) in an aqueous solution of pH 7.0 for dopamine (DA) detection. The ErGO/MWCNTs/PPy nanocomposites show enhanced electrochemical performance due to the strong $\pi-\pi^{*}$ stacking interactions among ErGO, MWCNTs, and PPy. The efficient interaction of the nanocomposites is confirmed by evaluating its physical and electrochemical characteristics using field-emission scanning electron microscopy, Raman spectroscopy, electrochemical impedance spectroscopy, cyclic voltammetry, and amperometry. The deposited nanocomposites are highly stable on the substrates and possess high surface areas, which is vital to improve the sensitivity and selectivity for DA detection. The controlled deposition of the ErGO/MWCNTs/PPy nanocomposites can provide enhanced electrochemical detection of DA. The sensor demonstrates a short time response within $2 \mathrm{~s}$ and is a highly sensitive approach for DA detection with a dynamic linear range of $25-1000 \mathrm{nM}\left(R^{2}=0.999\right)$. The detection limit is estimated to be $2.3 \mathrm{nM}$, and the sensor sensitivity is calculated to be $8.96 \mu \mathrm{A} \mathrm{MM}^{-1} \mathrm{~cm}^{-2}$, with no distinct responses observed for other biological molecules.
\end{abstract}

Keywords: Dopamine, Nanocomposites, Single-step deposition, Electrochemical sensor, Neutral pH

\section{Introduction}

The production of electrochemically fabricated integrated nanocomposites (containing carbon-based nanomaterials, metal nanoparticles, and conducting polymers) on the surface of a transducer using a binder-free process increases the transducer's electrochemical stability and film-forming ability

\footnotetext{
*Correspondence: jhyoon@kbsi.re.kr; s.c.chang@pusan.ac.kr

${ }^{\dagger}$ Vijayaraj Kathiresan and Dinakaran Thirumalai contributed equally to this work.

${ }^{5}$ Busan Center, Korea Basic Science Institute, Busan 46241, Republic of Korea 2Department of Cogno-Mechatronics Engineering, College of Nanoscience and Nanotechnology, Pusan National University, Busan 46241, Republic of Korea

Full list of author information is available at the end of the article
}

(Tang et al. 2015; Feng et al. 2011; Huang et al. 2014). A variety of conductive nanomaterials, in particular graphene, a two-dimensional nanostructured material, have attracted considerable attention because of their fascinating properties, such as large specific area, electrical conductivity, mechanical stiffness, and biocompatibility, making them potential candidates for biosensing devices (Geim and Novoselov 2007; Rabti et al. 2016; Sun et al. 2015). Nowadays, researchers focus on several procedures and approaches to produce graphene; in particular, electrochemical deposition has emerged as one of the most significant methods to fabricate graphene because it saves labor; is convenient, inexpensive, non-toxic, rapid, environmentally friendly, and safe; and does not 
require binders (Gao et al. 2010; Wei et al. 2015; Guo et al. 2009).

However, fabricating graphene-based nanocomposites as biosensing platforms through a simple and convenient "single-step" electrochemical approach without using binders or any additional treatments and sophisticated procedures is still a challenge. This approach incorporates graphene oxide (GO), polypyrrole (PPy) and multiwalled carbon nanotubes (MWCNTs) as the starting materials to electrochemically prepare nanocomposites on a transducer surface. Most previous studies on this the preparation of graphene-based nanocomposite use a "multi-step" electrochemical deposition strategy. For instance, acupuncture needle surface electrodeposited graphene-gold nanoparticles (AuNPs) for dopamine (DA) detection (Tang et al. 2015). These processes of decoration and conjugation involve complicated modification steps and harsh preparation conditions. Therefore, there is a demand for a "single-step" electrochemical deposition process that is simple and cost-effective. Modifying an electrode using graphene, MWCNTs, and PPy to produce electrochemically integrated components can enhance its electrochemical properties (Li et al. 2014; Seenivasan et al. 2015; Yang et al. 2016). A previous report has demonstrated a multi-step procedure for electrochemically depositing a MWCNT/PPy composite onto a gold surface for DNA detection (Miodek et al. 2015). Si et al. developed a twostep electrochemical approach to fabricate DA biosensor based on an ErGO/PPy composite prepared in lithium perchlorate $\left(\mathrm{LiClO}_{4}\right)$ medium. This strategy revealed that the $\pi-\pi^{*}$ interaction between the ErGO/PPy composite and the DA molecules remarkably increases the electrode sensitivity (Si et al. 2011). To the best of our knowledge, a single-step electrochemical strategy to prepare the ErGO/MWCNTs/PPy nanocomposite in a neutral solution for application in a DA biosensor has not been reported yet.

DA is a catecholamine neurotransmitter that plays an important role in the human central nervous system. Abnormal levels of DA are connected to several neurological disorders, e.g., schizophrenia, Parkinson's disease, and Huntington's disease (Schultz 1997; Ali et al. 2007). Until now, various analysis techniques have been established for DA sensing; in particular, electrochemical methods have attracted considerable attention owing to their simple operation, rapid response, low instrumental expense, and high sensitivity and selectivity (Keerthi et al. 2019) (Mercante et al. 2015). However, the selectivity of conventional electrodes for DA is not satisfactory because of the overlapping in the electrochemical potential window of DA with those of many other substances in the urine, blood, and the central nervous system (e.g., ascorbic acid (AA)). Enzymatic-based methods have attracted considerable attention due to their high sensitivity and comparative low cost. Despite these benefits, these methods are not widely used due to their low stability and complicated process of binding the enzyme to the electrode surface (Njagi et al. 2010). In order to avoid these complications, non-enzymatic electrode modification methods using carbon, metal, and polymerbased nanomaterials have received considerable attention due to the more robust and larger surface area to enhance selectivity, sensitivity, and stability of DA detection (Tan et al. 2015; Ma et al. 2020).

In this study, a new strategy for the fabrication of the nanocomposite-based biosensor for DA detection using a "single-step" electrochemical approach in an aqueous solution of $\mathrm{pH} 7.0$ without any additional treatment has been proposed. This process is schematically presented in Scheme 1. We prepared the nanocomposite by dropcasting a homogeneous mixture of GO, MWCNTs, and PPy on a transducer surface, producing an ErGO/ MWCNT/PPy nanocomposite. The ErGO/MWCNTs/ PPy nanocomposite was realized by the strong electrostatic force between the amino group of Py and the carboxylic group of GO and MWCNTs. Preparation of the nanocomposite in a neutral solution enabled costeffective synthesis and high electrocatalytic activity.

\section{Experimental \\ Reagents and instruments}

Graphite, MWCNTs (outer diameter: 6-9 nm; diameter: $5.5 \mathrm{~nm}$; length: $5 \mu \mathrm{m}$ and $>95 \%$ purity), pyrrole monomer, dopamine hydrochloride, epinephrine (EP), norepinephrine (NEP), ascorbic acid (AA), uric acid (UA), $\mathrm{Na}_{2} \mathrm{HPO}_{4}, \mathrm{NaH}_{2} \mathrm{PO}_{4}, \mathrm{~K}_{3}\left[\mathrm{Fe}(\mathrm{CN})_{6}\right]$, and $\mathrm{H}_{2} \mathrm{SO}_{4}$ were purchased from Sigma Aldrich, USA. All chemicals were of analytical grade and used as received. All aqueous solutions were prepared using deionized water (Milli-Q water purifying system, $18 \mathrm{M} \Omega \cdot \mathrm{cm}$ ).

Cyclic voltammetry (CV) and chronoamperometry (CA) were performed using a potentiostat (CompactStat Ivium Technology, the Netherlands). Electrochemical impedance spectroscopy (EIS) was recorded using an electrochemical analyzer (VersaSTAT, Princeton Applied Research, USA) in the frequency range of 100 to $0.1 \mathrm{~Hz}$ at a DC potential of $250 \mathrm{mV}$ and AC potential of $\pm 5 \mathrm{mV}$. A three-electrode system was used with a bare glassy carbon electrode (GCE, $3 \mathrm{~mm}$ in diameter) as the working electrode, $\mathrm{Ag} / \mathrm{AgCl}$ as the reference electrode, and a platinum wire as the auxiliary electrode. The nanocomposites were deposited on iridium tin oxide (ITO) substrates to study their surface characteristics by field-emission scanning electron microscopy (FE-SEM) and Raman spectroscopy. SEM characterization was performed on a field-emission scanning electron microscope (Hitachi S-4200, Japan) operated at $15 \mathrm{kV}$ and 


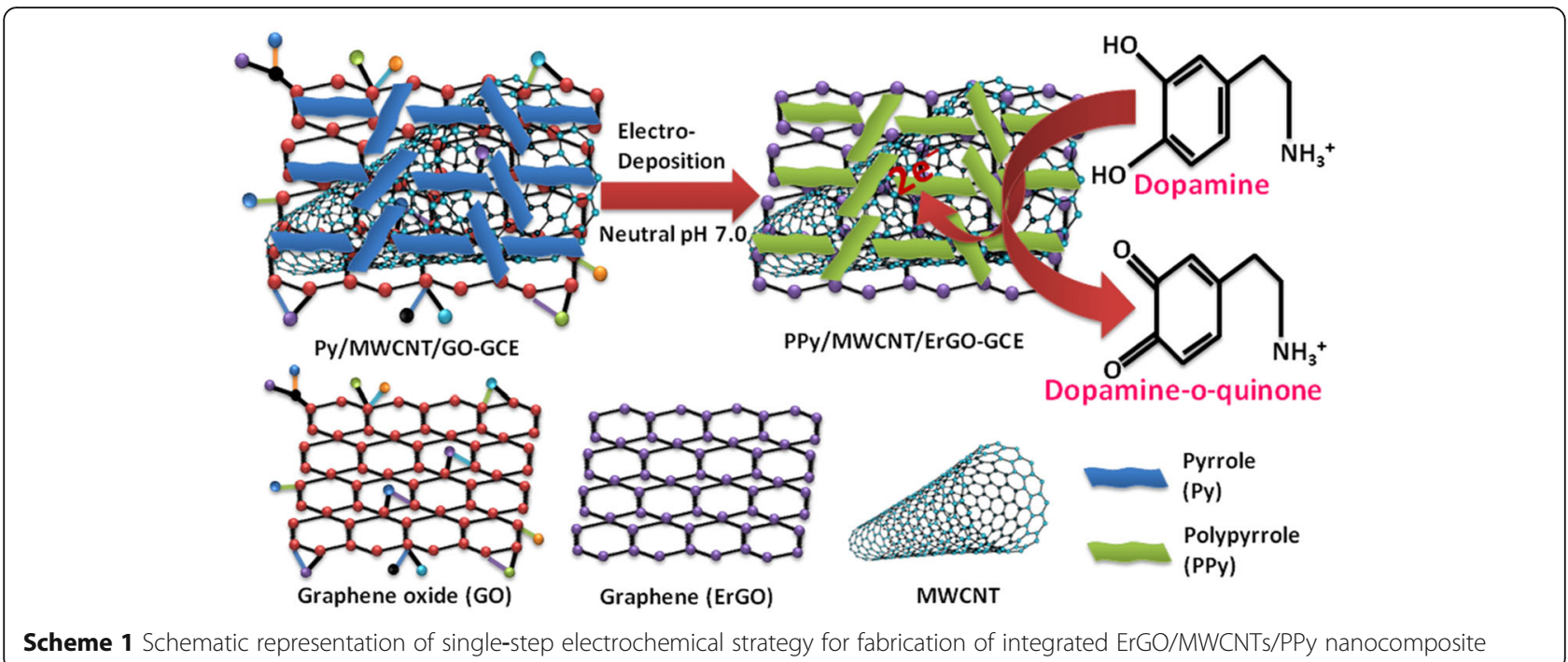

Scheme 1 Schematic representation of single-step electrochemical strategy for fabrication of integrated ErGO/MWCNTs/PPy nanocomposite

150 W. Raman spectra were observed on a LabRAM HR Raman spectrometer (HORIBA Scientific, France).

\section{Electrochemical synthesis of the ErGO/MWCNTs/PPy nanocomposite}

Graphene oxide was synthesized from graphite by modified Hummer's method (Hummers and Offeman 1958). The pristine MWCNTs were treated by mixing in a solution containing $\mathrm{HNO}_{3} / \mathrm{H}_{2} \mathrm{SO}_{4}(1: 1, \mathrm{v} / \mathrm{v})$ according to a procedure described previously (Woo et al. 2012). GO/ MWCNTs/Py dispersion was prepared by mixing $10 \mathrm{mg}$ of GO with $5 \mathrm{mg}$ of MWCNTs dispersed in $14.85 \mathrm{~mL}$ of 1 $\mathrm{M} \mathrm{H}_{2} \mathrm{SO}_{4}$, and then $0.15 \mathrm{~mL}$ of $0.15 \mathrm{M}$ Py monomer was added to form a homogeneous brown dispersion. This dispersion was magnetically stirred for $30 \mathrm{~min}$ and then sonicated for $20 \mathrm{~min}$ under ambient conditions. After the dispersion was centrifuged for $10 \mathrm{~min}$ at $10000 \mathrm{rpm}$, the residue was washed with water three times to remove any loosely adsorbed carbon-containing impurities and Py monomer. The obtained solid was dispersed again into 15 $\mathrm{mL}$ distilled water to form a $1 \mathrm{mg} \mathrm{mL}^{-1}$ suspension. The products of the GO/MWCNTs/Py dispersion were collected and stored at $4{ }^{\circ} \mathrm{C}$ until further use. A bare GCE was rinsed with water and polished using $0.3 \mu \mathrm{m}$ alumina slurries. The polished GCE was sonicated in ethanol and water for $10 \mathrm{~min}$ each. Then, the sonicated GCE was rinsed with water and dried under ambient conditions. The GO/MWCNTs/Py dispersion $(8 \mu \mathrm{L})$-modified GCE was prepared and used for electrochemical deposition. The CV of the GCE/GO/MWCNTs/Py composite was performed by cycling between $-1.4 \mathrm{~V}$ and $+0.8 \mathrm{~V}$ at a potential scan rate of $50 \mathrm{mV} \mathrm{s}^{-1}$ in phosphate-buffered saline (PBS, pH 7.0); 15 cycles were performed. Subsequently, the obtained GCE/ErGO/MWCNT/PPy nanocomposite biosensor was rinsed with water and dried in air.

\section{Results and discussion}

Physicochemical characterization of transducer surface

FE-SEM images of PPy (A), GO (B), ErGO (C), ErGO/PPy (D), ErGO/MWCNTs/PPy (E), and MWCNTs (F) are shown in Fig. 1. The pure PPy had a nanosphere-like structure with a diameter of around $200 \mathrm{~nm}$ (Jung et al. 2009). GO possessed a well aggregated, crumbled, and thick-layered structure. After electrochemical deposition of GO, it could be seen that the ErGO film was covered with single or ultrathin layers and showed a wrinkled sheet-like structure (Du et al. 2011). This structure could effectively improve the electrical conductivity and significantly increase the specific surface area, producing a good interface for the following modifications. The electrochemically deposited ErGO/PPy surface had a nanosphere-like morphology with several fine folds and ripple-like wrinkles (Bose et al. 2010) due to the electrostatic interaction between ErGO and PPy. The FE-SEM image of the electrochemically deposited ErGO/MWCNTs/ PPy nanocomposite showed a well-established interconnected structure of nanospheres, ultrathin layers, and nanowires. The integrated nanocomposite was effectively deposited on the substrate and grew more uniformly than PPy, GO, ErGO, ErGO/PPy, and MWCNTs. The resulting ErGO/MWCNTs/PPy nanocomposite showed significant advantages for DA biosensing applications.

Raman spectroscopy was used to characterize the chemical and structural changes of (a) PPy, (b) GO, (c) ErGO, (d) ErGO/PPy, (e) ErGO/MWCNTs/PPy, and (f) MWCNTs (Fig. 2A). For PPy, the characteristic bands appeared at $1338 \mathrm{~cm}^{-1}$ and $1574 \mathrm{~cm}^{-1}$, corresponding to the pyrrole-ring stretching and $\mathrm{C}=\mathrm{C}$ bond stretching, respectively (Liu 2004). GO showed D and G bands at $1350 \mathrm{~cm}^{-1}$ and $1585 \mathrm{~cm}^{-1}$, respectively, corresponding to the characteristic bands observed previously (Gao et al. 2011). After the deposition of GO by potential 

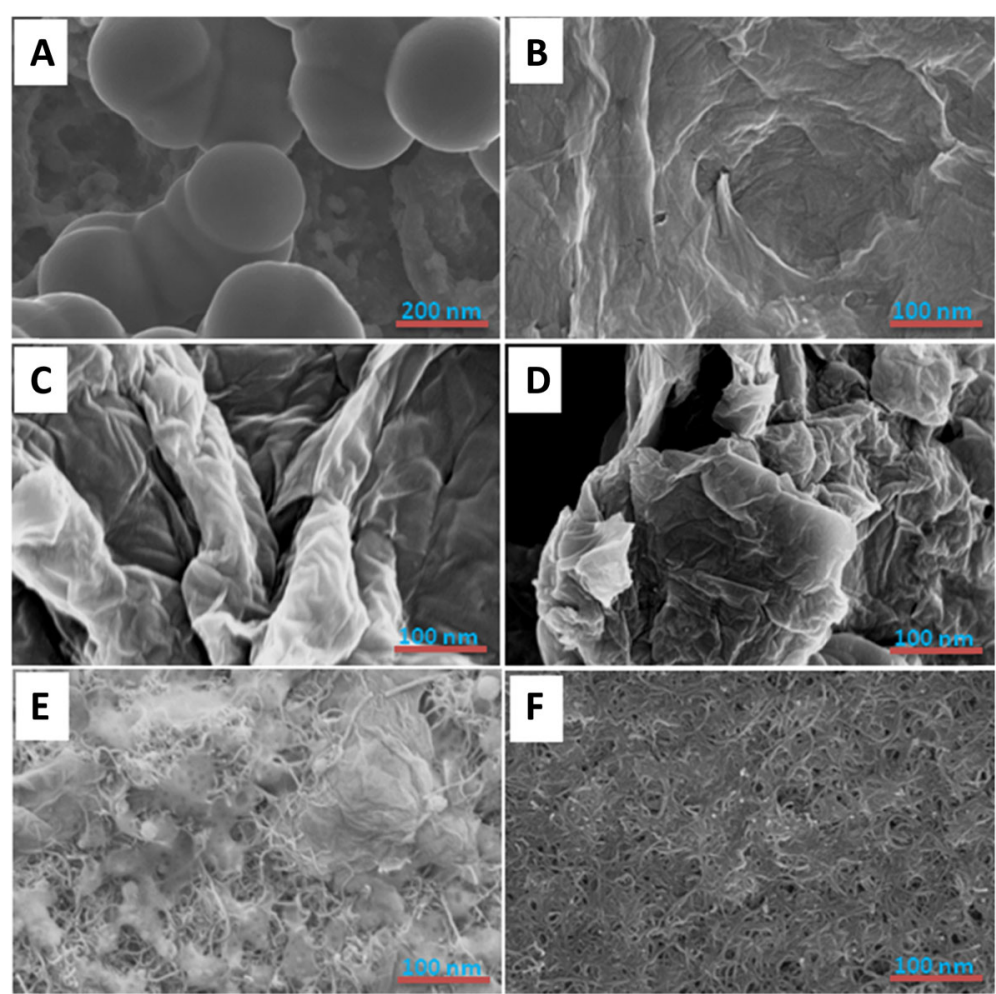

Fig. 1 FE-SEM images of PPy (a), GO (b), ErGO (c), ErGO/PPy (d), ErGO/MWCNTs/PPy (e), and MWCNTs (f)

cycling, the formation of ErGO led to a significant increase in the intensity of the D and G bands. The characteristic D band was found at $1350 \mathrm{~cm}^{-1}$ in both ErGO and ErGO/PPy, while the characteristic G band was located at $1585 \mathrm{~cm}^{-1}$ in ErGO and shifted to $1590 \mathrm{~cm}^{-1}$ in $\mathrm{ErGO} / \mathrm{PPy}$ with the decrease in the intensity, which was attributed to the repaired defects in ErGO due to the elimination of oxygen-containing functional groups from GO (Bose et al. 2010). The Raman spectrum of the ErGO/MWCNTs/PPy nanocomposite showed two characteristic bands at $1350 \mathrm{~cm}^{-1}$ and $1585 \mathrm{~cm}^{-1}$ with a significant increase in the intensity after it was incorporated in the MWCNT with the EGO/PPy matrix, indicating a strong interaction between graphitic allotropes and PPy due to $\pi-\pi^{*}$ electron interaction between ErGO or MWCNTs and PPy (Elnaggar et al. 2017). The increase in the intensity of D and G bands of the MWCN Ts after acid treatment when compared to those of the ErGO/MWCNTs/PPy nanocomposite indicated the increased defect concentration of the MWCNTs (Vinayan
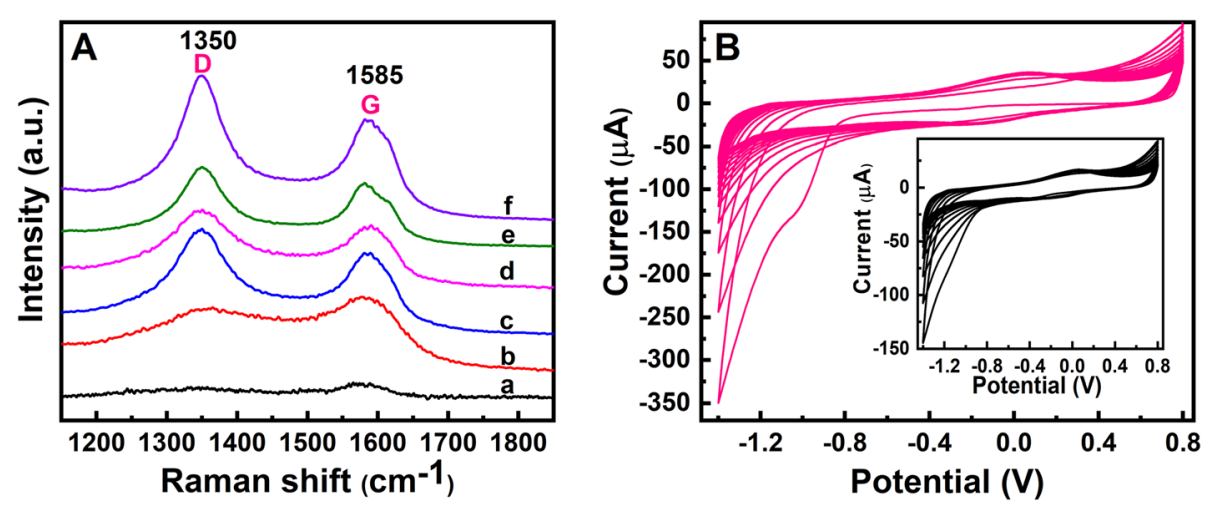

Fig. 2 A Raman spectra of (a) PPy, (b) GO, (c) ErGO, (d) ErGO/PPy, (e) ErGO/MWCNT/PPy, and (f) MWCNTs. b CV curves of the electrochemical deposition of GCE-GO/MWCNT/Py in $\mathrm{N}_{2}$ saturated $0.1 \mathrm{M} \mathrm{PBS}$ ( $\mathrm{pH} 7.0$ ) at a scan rate $50 \mathrm{mVs}^{-1}$. Inset: CV curve of the electrochemical deposition of GCE-GO/Py 
et al. 2012). The Raman spectra revealed that the intensity ratios $\left(I_{\mathrm{D}} / I_{\mathrm{G}}\right)$ of $\mathrm{GO}, \mathrm{ErGO}, \mathrm{ErGO} / \mathrm{PPy}, \mathrm{ErGO} /$ MWCNTs/PPy, and MWCNTs were 0.81, 0.88, 0.58, 1.16 , and 0.97 , respectively. This result confirms the successful deposition of the ErGO/MWCNTs/PPy nanocomposite on the GCE surface could serve as a favorable platform for electrochemical studies.

The ErGO/MWCNTs/PPy nanocomposite was prepared from a homogeneous dispersion of GO, MWCN Ts, and Py in an aqueous solution of $\mathrm{pH} 7.0$ by a singlestep electrodeposition approach. Figure $2 \mathrm{~b}$ shows the CV curves of the GO/MWCNT/Py dispersion in the potential window of $-1.4 \mathrm{~V}$ to $+0.8 \mathrm{~V}$ vs. $\mathrm{Ag} / \mathrm{AgCl}$ for 15 cycles at a scan rate of $50 \mathrm{mVs}^{-1}$. The positively charged Py monomer was homogeneously adsorbed over the negatively charged GO interconnected with MWCNTs via electrostatic interactions between the amino group of Py and the oxygen functionalities on the GO surface ( $\mathrm{Si}$ et al. 2011). The slight decrease in the characteristic peaks indicates the successful formation of nanocomposites over the GCE, with increasing the number of potential scanning cycles. The cathodic peak at $-1.02 \mathrm{~V}$ was attributed to the irreversible electrochemical reduction of $\mathrm{GO}$ and the redox peaks at $0.04 \mathrm{~V}$ and $-0.12 \mathrm{~V}$ were ascribed to the growth of PPy on the GCE. As a system, the electrochemically deposited ErGO/MWCNTs/PPy nanocomposite exhibited better cycling performance (2.3-fold) than ErGO/PPy (inset, Fig. 2B). This result showed that the integrated nanocomposite was highly stable on the electrode surface and the more active sites in MWCNTs were very helpful for the reduction of GO (Huang et al. 2014). The electrochemically deposited nanocomposite was successfully formed using a convenient and environment friendly process, and this nanocomposite has a great potential for use in electrochemical biosensor applications.

The electrochemical characteristics of the nanocomposite on the GCE were studied in a $5 \mathrm{mM} \mathrm{K}_{3} \mathrm{Fe}(\mathrm{CN})_{6}$ solution containing $0.1 \mathrm{M} \mathrm{KCl}$ by the $\mathrm{CV}$ experiments.
As shown in Fig. 3A, PPy (curve a) showed no redox peak currents and peak potential shifts; this is due the weak electrical conductivity caused by the insufficient polymerization of PPy in the aqueous solution ( $\mathrm{pH} 7.0)$. Compared to PPy, the redox peak current of ErGO/PPy (curve b) increased significantly. After incorporating the MWCNTs with the GO and Py dispersion, the obtained mixture was deposited on the GCE to get GCE/ErGO/ MWCNTs/PPy (curve c) and the redox peak current increased remarkably because of the high conductivity and large surface area of MWCNTs, which greatly promoted electron transfer. Thus, the redox peak current of ErGO/MWCNTs/PPy $(60.69 \mu \mathrm{A})$ was 1.2 and 2.0 times greater than that of $\mathrm{ErGO} / \mathrm{PPy}(49.71 \mu \mathrm{A})$ and $\mathrm{PPy}$ $(31.01 \mu \mathrm{A})$, respectively, due to the high electron transfer efficiency as well as large effective surface area and enhanced electrical properties.

The EIS spectra were obtained to test the interface properties and confirm the stepwise changes on the GCE surface. Figure 3B shows the EIS spectra of pure PPy (curve a), ErGO/PPy (curve b), and ErGO/ MWCNT/PPy (curve c) in the frequency range from 100 $\mathrm{KHz}$ to $0.1 \mathrm{~Hz}$ in a $5 \mathrm{mM} \mathrm{K}{ }_{3} \mathrm{Fe}(\mathrm{CN})_{6}$ solution containing $0.1 \mathrm{M} \mathrm{KCl}$. The semicircle diameter of the Nyquist plots represents the charge-transfer resistance $\left(R_{\mathrm{ct}}\right)$ of the redox probe at the electrode/electrolyte interface (Wang et al. 2014). When PPy was electrodeposited on the GCE, the semicircle diameter sharply increased because the low electrical conductivity of PPy in the aqueous solution led to insufficient polymerization of PPy. Compared with that of PPy, the electrochemical deposition of ErGO/PPy showed a decreased $R_{\mathrm{ct}}$ value, showing improved electrical conductivity. Electrochemical deposition of ErGO/MWCNT/PPy showed a straight line, suggesting a decrease in the $R_{\mathrm{ct}}$ value due to the more efficient use of active sites of the MWCNTs. From the Nyquist plots, the $R_{\mathrm{ct}}$ of the ErGO/MWCNT/PPy-modified electrode ( $31 \Omega$ ) was found to be smaller than those of ErGO/PPy (168 $\Omega$ ) and PPy (443 $\Omega$ ). These data
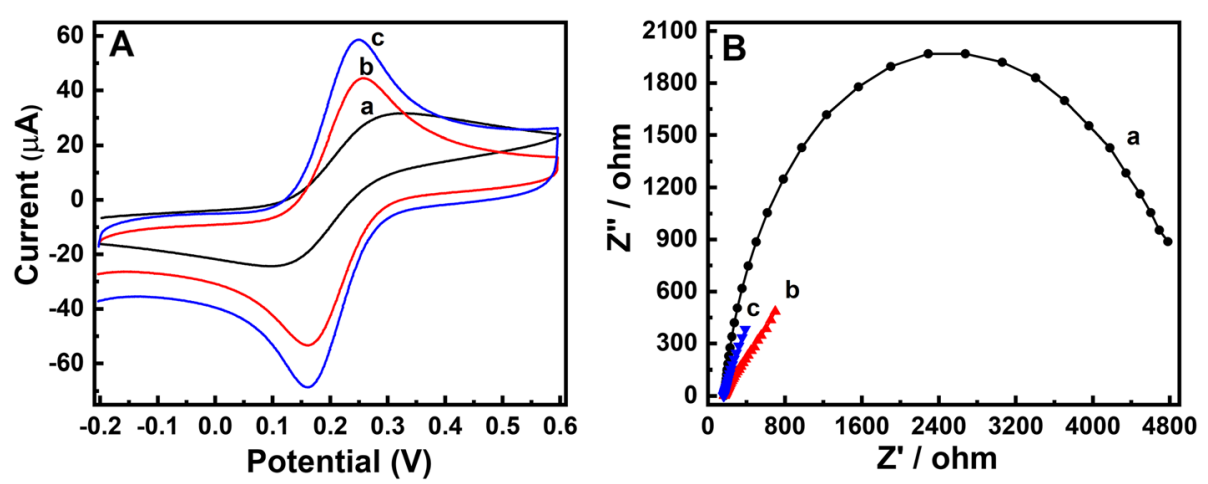

Fig. 3 a CV and $\mathbf{b}$ EIS of a GCE-PPy, b GCE-ErGO/PPy, and c GCE-ErGO/MWCNT/PPy in $5 \mathrm{mM} \mathrm{K} \mathrm{K}_{3} \mathrm{Fe}(\mathrm{CN})_{6}$ containing $0.1 \mathrm{M} \mathrm{KCl}$. CV scan rate: 50 $\mathrm{mVs}^{-1}$; impedance frequency range: $100 \mathrm{KHz}$ to $0.1 \mathrm{~Hz}$ 
clearly indicated that the ErGO/MWCNT/PPy nanocomposite exhibited 5.5 and 14.3 times decreased $R_{\mathrm{ct}}$ values than ErGO/PPy and PPy, respectively, which indicated the former's enhanced electrical conductivity and potential for application as an ideal platform. This result was also related to the $\mathrm{CV}$ results.

The electrochemical properties of the ErGO/MWCNTs/ PPy-modified electrode for DA current response were investigated in terms of applied potential, $\mathrm{pH}$, and optimal temperatures. To study the dependence of DA detection on applied potential, CA measurements were performed to observe the current response at different potentials in the presence of $250 \mathrm{nM} \mathrm{DA}$ in the potential range 0.1$0.3 \mathrm{~V}$ (Fig. 4a). The current response increased with increasing potential and reached its maximum value at a potential of $0.25 \mathrm{~V}$. On further increasing the potential to $0.3 \mathrm{~V}$, the current response of DA decreased slightly. Therefore, $0.25 \mathrm{~V}$ was selected to be the optimal potential of the sensor.

The effect of $\mathrm{pH}$ on the electrochemical behavior of DA in the ErGO/MWCNT/PPy-modified electrode was also evaluated by CA analysis. As shown in Fig. 4b, the current response increased gradually with the addition of $250 \mathrm{nM}$ DA for $\mathrm{pH}$ values of 5.0-9.0 and the highest current response was achieved at a $\mathrm{pH}$ 7.0. On further increasing the $\mathrm{pH}$, the current response slightly decreased. Therefore, the $\mathrm{pH}$ value 7.0 was chosen as the optimal condition and used in subsequent electrochemical experiments.

The influence of temperature on the electrochemical behavior of DA in the ErGO/MWCNTs/PPy-modified electrode was investigated. As shown in Fig. 4c, the DA current response increased remarkably over the temperatures range $25-45^{\circ} \mathrm{C}$. It could be seen that the amperometric current response increased rapidly from 25 to $35^{\circ} \mathrm{C}$ and then slightly decreased from 40 to $45^{\circ} \mathrm{C}$. Therefore, the optimal temperature was determined to be $35^{\circ} \mathrm{C}$ and it was used for further electrochemical experiments for DA detection.

\section{Electrochemical evolution of nanocomposite for DA detection}

The electrocatalytic behavior of DA in different modified electrodes was tested by $\mathrm{CV}$ and the results are shown in Fig. 5A. It was observed that the current response of DA was insignificant in GCE-PPy (curve a) owing to its poor electrical conductivity. The current response of DA in $\mathrm{ErGO/PPy} \mathrm{(curve} \mathrm{b)} \mathrm{was} \mathrm{higher} \mathrm{than} \mathrm{that} \mathrm{in} \mathrm{PPy,}$ which suggested fast electron transfer to DA. Compared to PPy $(2.17 \mu \mathrm{A})$ and ErGO/PPy $(9.11 \mu \mathrm{A}), \mathrm{ErGO} /$ MWCNTs/PPy $(66.36 \mu \mathrm{A})$ exhibited a significantly better current response (curve c) due to its higher electrocatalytic efficiency as well as the synergistic effect of ErGO, MWCNTs, and PPy (Ling et al. 2013). Using Randles-
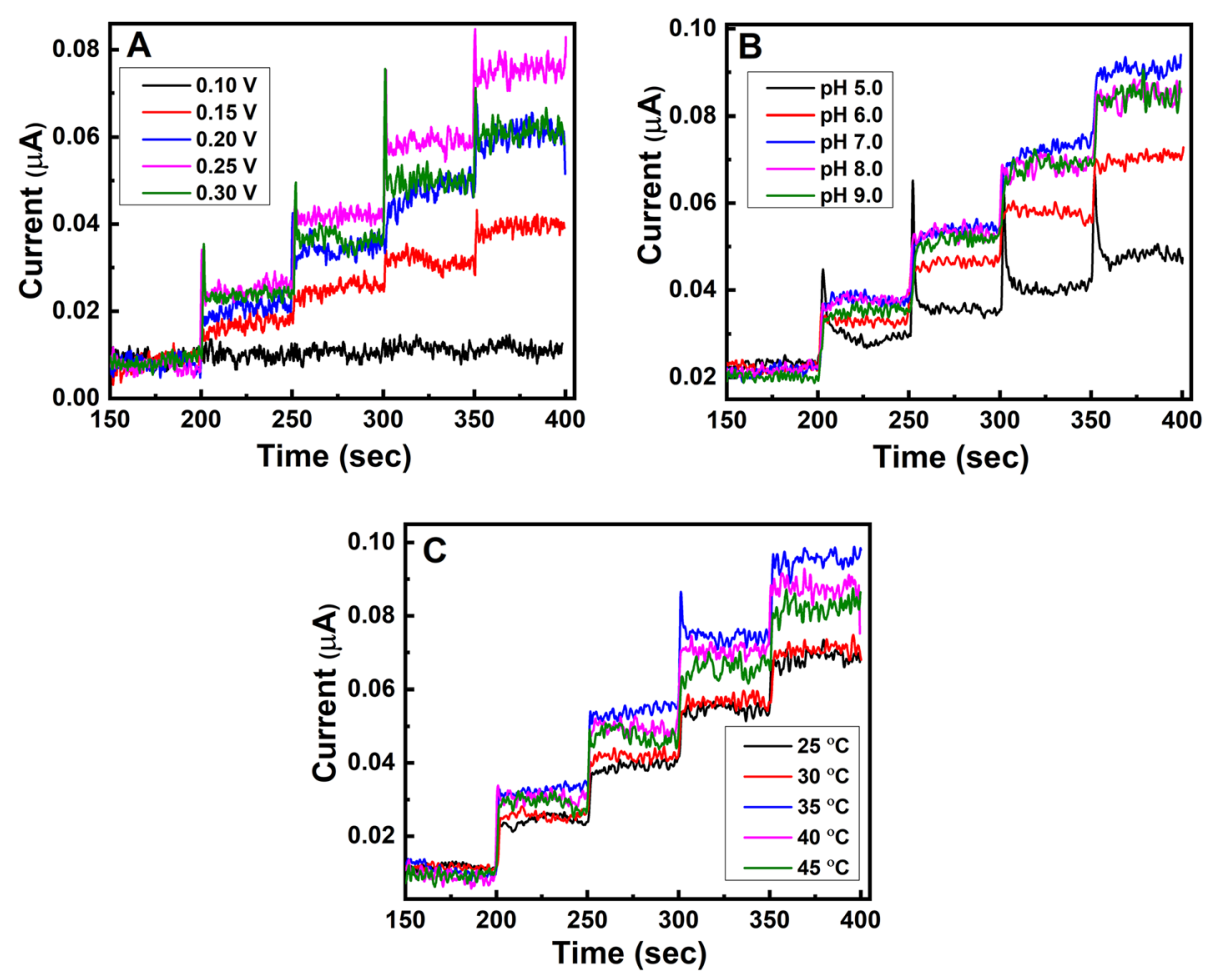

Fig. 4 a Amperometric current response of GCE/ErGO/MWCNTs/PPy for DA at different potentials, $\mathbf{b}$ at different pH values, and $\mathbf{c}$ at different temperatures in $0.1 \mathrm{M}$ PBS (pH 7.0) containing $250 \mathrm{nM}-1000 \mathrm{nM}$ DA 

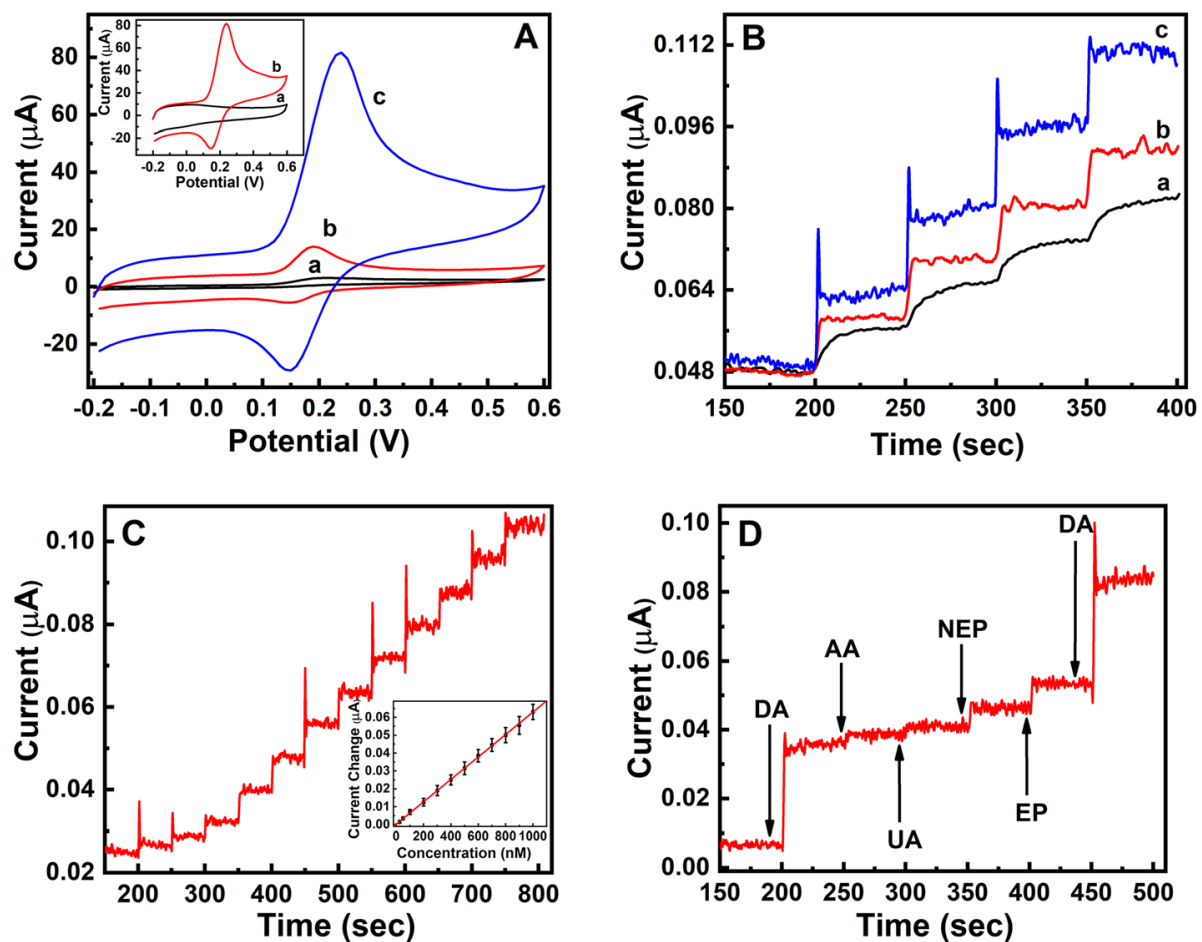

Fig. 5 A CVs of a GCE/PPy, b GCE/ErGO/PPy, and c GCE/ErGO/MWCNTs/PPy in $0.1 \mathrm{M} \mathrm{PBS} \mathrm{(pH} \mathrm{7.0)} \mathrm{containing} 50 \mu \mathrm{M}$ DA at a scan rate of 50 $\mathrm{mVs}^{-1}$. Inset: CV curves of GCE/ErGO/MWCNTs/PPy in the absence (a) and presence (b) of $50 \mu \mathrm{M}$ DA. B Amperometric response of $\mathbf{a}$ GCE/PPy, $\mathbf{b}$ GCE/ErGO/PPy, and c GCE/ErGO/MWCNTs/PPy in $0.1 \mathrm{M} \mathrm{PBS} \mathrm{pH} \mathrm{(7.0)} \mathrm{containing} 250 \mathrm{nM} \mathrm{DA.} \mathrm{C} \mathrm{Amperometric} \mathrm{response} \mathrm{of} \mathrm{GCE/ErGO/MWCNTs/PPy}$ at $0.25 \mathrm{~V}$ in $0.1 \mathrm{M} \mathrm{PBS} \mathrm{pH}(7.0)$ with successive addition of DA. Inset: Calibration curve for the DA sensor. D Amperometric response of GCE/ErGO/ MWCNTs/PPy for the addition of DA, AA, UA, NEP, and EP in $0.1 \mathrm{M} \mathrm{PBS} \mathrm{pH} \mathrm{(7.0)}$

Sevcik equation, the electrochemically active surface areas were also estimated (Eq. (1)).

$$
i_{p a}=2.69 \times 10^{5} n^{3 / 2} A C D^{1 / 2} v^{1 / 2}
$$

where $i_{\mathrm{pa}}$ is the anodic peak current (A), $n$ is the number of electrons $(n=2), A$ is the electrochemically active surface area $\left(\mathrm{cm}^{2}\right), D$ is the diffusion coefficient $(3.29 \times$ $\left.10^{-6} \mathrm{~cm}^{2} \mathrm{~s}^{-1}\right)$ and $C$ is the concentration of DA (50 $\times$ $\left.10^{-6} \mathrm{M}\right)$, and $v$ is the scan rate $\left(V \mathrm{~s}^{-1}\right)$. According to the equation, the electrochemically active surface area of the GCE-PPy, GCE-ErGO/PPy, and GCE-ErGO/MWCNTs/ PPy was estimated to be $0.142 \mathrm{~cm}^{2}, 0.586 \mathrm{~cm}^{2}$, and 4.34 $\mathrm{cm}^{2}$, respectively. The GCE-ErGO/MWCNTs/PPy electrode possesses higher electroactive surface area which enhances the oxidation of DA. Further, the ErGO/ MWCNTs/PPy-modified GCE showed (a) no distinct response in the absence of DA and (b) a well-defined response in the presence of DA (inset, Fig. 5A). It was clear that the electrochemical production of the ErGO/ MWCNTs/PPy nanocomposite surface was 7.3 and 30.6 times higher than that of the ErGO/PPy and PPy surfaces, respectively. Therefore, controlling the specific surface area and improving the electrical conductivity were effective ways to develop a platform for highly sensitive DA detection.

\section{Sensor performance and calibration for DA}

Electrochemical sensing of the PPy (a), ErGO/PPy (b), and ErGO/MWCNTs/PPy (c) was tested using amperometric measurements to investigate their DA detection ability. The sensing was performed by adding $250 \mathrm{nM}$ DA in $0.1 \mathrm{M}$ PBS (pH 7.0) at an applied potential of 0.25 $\mathrm{V}$. As shown in Fig. 5B, the highest sensing response was observed for the ErGO/MWCNTs/PPy electrode, indicating that it had a stronger electrocatalytic effect toward DA than ErGO/PPy and PPy. According to the amperometric response, the sensitivity of $\mathrm{PPy}, \mathrm{ErGO} / \mathrm{PPy}$, and $\mathrm{ErGO} / \mathrm{MWCNTs} / \mathrm{PPy}$ was calculated to be 7.56 , 7.73 , and $8.96 \mu \mathrm{A} \mu \mathrm{M}^{-1} \mathrm{~cm}^{-2}$, respectively. These values indicated that the single-step electrochemically deposited ErGO/MWCNTs/PPy nanocomposites showed improved synergistic properties, which could enhance the electrocatalytic effect and provide a larger electroactive surface area to enhance the sensitivity for DA detection.

The calibration curves of the ErGO/MWCNTs/PPy nanocomposite sensor for DA detection were plotted. The Fig. 5C displays the amperometric response of the ErGO/MWCNT/PPy electrode in 0.1 M PBS ( $\mathrm{pH} 7.0$ ) 
Table 1 Comparison of the electrochemical performance of different electrode materials for DA detection

\begin{tabular}{|c|c|c|c|c|c|c|}
\hline $\begin{array}{l}\text { Electrode } \\
\text { materials }\end{array}$ & $\begin{array}{l}\text { Analytical } \\
\text { technique }\end{array}$ & $\begin{array}{l}\text { Linear range } \\
(\mu \mathrm{M})\end{array}$ & $\begin{array}{l}\text { Detection limit } \\
(\mu \mathrm{M})\end{array}$ & $\begin{array}{l}\text { Sensitivity } \\
\left(\mu \mathrm{A} \mu \mathrm{M}^{-1} \mathrm{~cm}^{-2}\right)\end{array}$ & Interferences & References \\
\hline GA-RGO/AuNPs & DPV & $0.01-100.3$ & 2.6 & 3.58 & UA, AA & (Thirumalraj et al. 2017) \\
\hline ErGO/PEDOT & Amperometry & $0.1-175$ & 39 & - & $A A, \cup A$ & (Wang et al. 2014) \\
\hline$C B$ & sWV & $0.1-20$ & 60 & 1.81 & $A A, \cup A$ & (Jiang et al. 2016) \\
\hline ErGO/PPy & DPV & $0.1-150$ & 23 & - & $A A, \cup A$ & (Si et al. 2011) \\
\hline $\mathrm{GO} / \mathrm{C} 60$ & DPV & $0.02-73.5$ & 8.0 & 4.23 & - & (Thirumalraj et al. 2016) \\
\hline $\mathrm{S}-\mathrm{Fe}_{2} \mathrm{O}_{3}$ & Amperometry & $0.2-107$ & 31.25 & 0.67 & $\cup A, A A$ & (Chen et al. 2016) \\
\hline $\mathrm{PPy} / \mathrm{Ag} / \mathrm{PVP}$ & Amperometry & $0.01-0.090$ & 126 & 7.25 & $A A, \cup A, F A$ & $\begin{array}{l}\text { (Vellaichamy et al. } \\
\text { 2017) }\end{array}$ \\
\hline $\mathrm{Fe}_{3} \mathrm{O}_{4} / \mathrm{GNs} / \mathrm{NF}$ & DPV & $0.020-130$ & 7.0 & - & GLU, UA, AA & (Zhang et al. 2015) \\
\hline ErGO/MWCNTs/PPy & Amperometry & $0.025-1.0$ & 2.3 & 8.96 & $\begin{array}{l}\text { AA, UA, NEP, } \\
\text { EP }\end{array}$ & This work \\
\hline
\end{tabular}

GA gallic acid, $R G O$ reduced graphene oxide, AuNPs gold nanoparticles, ErGO electrochemically reduced graphene oxide, $P E D O T$ poly(3,4-ethylenedioxythiophene), $P P y$ polypyrrole, $\mathrm{CB}$ carbon block, $\mathrm{S}-\mathrm{Fe}_{2} \mathrm{O}_{3}$ shuttle-like iron(III) oxide, $\mathrm{PVP}$ polyvinylpyrrolidone, $\mathrm{Fe}_{3} \mathrm{O}_{4}$ iron (II, III) oxide, $\mathrm{GNs}$ graphene nanospheres, $N F$ nafion, $G \mathrm{O}$ graphene oxide, C60 fullerene

containing DA at an applied potential of $0.25 \mathrm{~V}$. The amperometric signal rapidly changed due to changes in the DA concentration, and the steady state current was achieved within $2 \mathrm{~s}$ after the addition of DA. The nanocomposite sensor exhibited a short time response of $2 \mathrm{~s}$ and a highly sensitive detection of DA with a dynamic linear range of $25-1000 \mathrm{nM}$ and a linear regression equation of $i(\mu \mathrm{A})=194.56 \mathrm{C}_{\mathrm{DA}}(\mathrm{nM})+62.73\left(R^{2}=\right.$ 0.999). The detection limit was estimated to be $2.3 \mathrm{nM}$, and the sensor sensitivity was calculated to be $8.96 \mu \mathrm{A \mu} \mu \mathrm{M}^{-1} \mathrm{~cm}^{-2}$. The inset figure shows the calibration curves for DA detection. These results indicated that the synergistic properties of the integrated nanocomposite could improve the electrochemical sensing performance by achieving the best linearity in a dynamic range of DA concentrations, high sensitivity, short response time, and the lowest limit of detection. Comparison with of the sensing performance of different electrode materials and analytical key parameters of some recently reported DA sensors are listed in Table 1. Therefore, the single-step synthesis of the integrated ErGO/MWCNT/PPy nanocomposite could provide a promising electrode material for the amperometric detection of DA.

Selectivity is one of the most important analytical factors of sensor performance for practical applications. Figure 5D presents the amperometric current response of the ErGO/MWCNT/PPy-modified electrode to the addition of $0.5 \mu \mathrm{M}$ DA, $1 \mu \mathrm{M}$ AA, $1 \mu \mathrm{M}$ UA, $1 \mu \mathrm{M}$ NEP, $1 \mu \mathrm{M}$ EP, and a second addition of $0.5 \mu \mathrm{M}$ DA. No distinct changes were observed in the amperometric responses of the other biological molecules (apart from DA) at the operating potential of $0.25 \mathrm{~V}$. These results indicated that the ErGO/MWCNT/PPy nanocomposite contains positively charged PPy, which could provide selective DA detection (Si et al. 2011).
The storage stability and reproducibility are other essential parameters for DA detection, and they were also evaluated by amperometric analysis. To investigate the reproducibility of the $\mathrm{ErGO} / \mathrm{MWCNT} / \mathrm{PPy}$ electrode, $0.5 \mu \mathrm{M}$ DA was added six times, and a relative standard deviation (RSD) of $5.43 \%$ was obtained. In addition, the storage stability of the sensor was studied by amperometric measurements. The current response of the sensor retained over $94 \%$ of its initial value for $0.5 \mu \mathrm{M}$ DA after 3 weeks, indicating the good stability of the sensors. Thus, the ErGO/MWCNT/PPy-modified electrode showed favorable reproducibility and acceptable stability for DA detection.

\section{Conclusions}

This study presents a single-step and controllable approach to prepare ErGO/MWCNT/PPy nanocomposite from a homogeneous mixed solution using electrochemical deposition in an aqueous solution of $\mathrm{pH}$ 7.0, without harsh conditions; this nanocomposite can used as a biosensor for DA detection. Our strategy is innovative in that it uses an aqueous solution ( $\mathrm{pH} 7.0)$, and it shows better electrochemical sensor applications that acidic solution-based methods. The electrochemically deposited nanocomposite shows significantly improved electrochemical performance by controlling its electroactive surface area, thus increasing the electron transfer rate and enhancing the electrode conductivity and sensor sensitivity. Further research could be required on the development of a biosensor for in vivo detection of DA in real samples.

\section{Abbreviations}

ErGO: Electrochemically reduced graphene oxide; MWCNTs: Multi-walled carbon nanotubes; PPy: Polypyrrole; DA: Dopamine; CV: Cyclic voltammetry; CA: Chronoamperometry; EIS: Electrochemical impedance spectroscopy; GCE: Glassy carbon electrode 


\section{Acknowledgements}

Not applicable.

\section{Authors' contributions}

VK, DT, JHY, and SCC designed and carried out the research and wrote the manuscript. TR and MY analyzed the data. JL and SK revised the manuscript. The authors read and approved the final manuscript.

\section{Funding}

This work was supported by a 2-Year Research Grant of Pusan National University.

\section{Availability of data and materials}

The datasets used and/or analyzed during the current study are available from the corresponding author on reasonable request.

\section{Competing interests}

The authors declare that they have no competing interests.

\section{Author details}

'Graduate Department of Chemical Materials, Pusan National University, Busan 46241, Republic of Korea. ${ }^{2}$ Department of Cogno-Mechatronics Engineering, College of Nanoscience and Nanotechnology, Pusan National University, Busan 46241, Republic of Korea. ${ }^{3}$ College of Pharmacy, Pusan National University, Busan 46241, Republic of Korea. ${ }^{4}$ Department of Chemistry, Pusan National University, Busan 46241, Republic of Korea. ${ }^{5}$ Busan Center, Korea Basic Science Institute, Busan 46241, Republic of Korea.

\section{Received: 2 September 2020 Accepted: 18 January 2021}

\section{Published online: 03 February 2021}

\section{References}

Ali SR, Ma Y, Parajuli RR, Balogun Y, Lai WY, He H. A nonoxidative sensor based on a self-doped polyaniline/carbon nanotube composite for sensitive and selective detection of the neurotransmitter dopamine. Anal Chem. 2007; 79(6):2583-7. https://doi.org/10.1021/ac0620680.

Bose S, Kuila T, Uddin ME, Kim NH, Lau AKT, Lee JH. In situ synthesis and characterization of electrically conductive polypyrrole/graphene nanocomposites. Polymer. 2010;51(25):5921-8. https://doi.org/10.1016/j. polymer.2010.10.014.

Chen A, Xu L, Zhang X, Yang Z, Yang S. Improving surface adsorption via shape control of hematite alpha- $\mathrm{Fe}_{2} \mathrm{O}_{3}$ nanoparticles for sensitive dopamine sensors. ACS Appl Mater Interfaces. 2016;8(49):33765-74. https://doi.org/10. 1021/acsami.6b11088.

Du D, Liu J, Zhang XY, Cui XL, Lin YH. One-step electrochemical deposition of a graphene- $\mathrm{ZrO}_{2}$ nanocomposite: preparation, characterization and application for detection of organophosphorus agents. J Mater Chem. 2011;21(22):80327. https://doi.org/10.1039/c1jm10696a.

Elnaggar EM, Kabel KI, Farag AA, Al-Gamal AG. Comparative study on doping of polyaniline with graphene and multi-walled carbon nanotubes. J Nanostruct Chem. 2017;7:75-83. https://doi.org/10.1007/s40097-017-0217-6.

Feng XM, Li RM, Ma YW, Chen RF, Shi NE, Fan QL, Huang W. One-step electrochemical synthesis of graphene/polyaniline composite film and its applications. Adv Funct Mater. 2011;21(15):2989-96. https://doi.org/10.1002/ adfm.201100038.

Gao H, Xiao F, Ching CB, Duan H. One-step electrochemical synthesis of PtNi nanoparticle-graphene nanocomposites for nonenzymatic amperometric glucose detection. ACS Appl Mater Interfaces. 2011;3(8):3049-57. https://doi. org/10.1021/am200563f

Gao XF, Jang J, Nagase S. Hydrazine and thermal reduction of graphene oxide: reaction mechanisms, product structures, and reaction design. J Phys Chem C. 2010;114(2):832-42. https://doi.org/10.1021/jp909284g.

Geim AK, Novoselov KS. The rise of graphene. Nat Mater. 2007;6(3):183-91. https://doi.org/10.1038/nmat1849.

Guo HL, Wang XF, Qian QY, Wang FB, Xia XH. A green approach to the synthesis of graphene nanosheets. ACS Nano. 2009;3(9):2653-9. https://doi.org/10. 1021/nn900227d

Huang $\mathrm{H}$, Chen $\mathrm{T}$, Liu X, Ma H. Ultrasensitive and simultaneous detection of heavy metal ions based on three-dimensional graphene-carbon nanotubes hybrid electrode materials. Anal Chim Acta. 2014;852:45-54. https://doi.org/ 10.1016/j.aca.2014.09.010.
Hummers WS, Offeman RE. Preparation of graphitic oxide. J Am Chem Soc. 1958; 80(6):1339. https://doi.org/10.1021/ja01539a017.

Jiang L, Nelson GW, Abda J, Foord JS. Novel modifications to carbon-based electrodes to improve the electrochemical detection of dopamine. ACS Appl Mater Interfaces. 2016;8:28338-48. https://doi.org/10.1021/acsami.6b03879.

Jung Y, Singh N, Choi KS. Cathodic deposition of polypyrrole enabling the onestep assembly of metal-polymer hybrid electrodes. Angew Chem. 2009; 48(44):8331-4. https://doi.org/10.1002/anie.200903596.

Keerthi M, Boopathy G, Chen S-M, Chen T-W, Lou B-S. A core-shell molybdenum nanoparticles entrapped f-MWCNT s hybrid nanostructured material based non-enzymatic biosensor for electrochemical detection of dopamine neurotransmitter in biological samples. Sci Rep. 2019;9(1):1-12.

Li P, Yang Y, Shi E, Shen Q, Shang Y, Wu S, Wei J, Wang K, Zhu H, Yuan Q, Cao A, Wu D. Core-double-shell, carbon nanotube@polypyrrole@ $\mathrm{MnO}_{2}$ sponge as freestanding, compressible supercapacitor electrode. ACS Appl Mater Interfaces. 2014;6(7):5228-34. https://doi.org/10.1021/am500579c.

Ling YY, Huang QA, Zhu MS, Feng DX, Li XZ, Wei Y. A facile one-step electrochemical fabrication of reduced graphene oxide-mutilwall carbon nanotubes-phospotungstic acid composite for dopamine sensing. J Electroanal Chem. 2013;693:9-15. https://doi.org/10.1016/j.jelechem.2013.01.001.

Liu YC. Characteristics of vibration modes of polypyrrole on surface-enhanced Raman scattering spectra. J Electroanal Chem. 2004;571(2):255-64. https://doi. org/10.1016/j.jelechem.2004.05.015.

Ma X, Gao F, Dai R, Liu G, Zhang Y, Lu L, Yu Y. Novel electrochemical sensing platform based on a molecularly imprinted polymer-decorated 3D-multiwalled carbon nanotube intercalated graphene aerogel for selective and sensitive detection of dopamine. Analytical Methods. 2020;12(14):1845-51.

Mercante LA, Pavinatto A, Iwaki LE, Scagion VP, Zucolotto V, Oliveira ON Jr, Mattoso LH, Correa DS. Electrospun polyamide 6/poly(allylamine hydrochloride) nanofibers functionalized with carbon nanotubes for electrochemical detection of dopamine. ACS Appl Mater Interfaces. 2015;7(8): 4784-90. https://doi.org/10.1021/am508709c.

Miodek A, Mejri N, Gomgnimbou M, Sola C, Korri-Youssoufi H. E-DNA sensor of Mycobacterium tuberculosis based on electrochemical assembly of nanomaterials (MWCNTs/PPy/PAMAM). Anal Chem. 2015;87(18):9257-64. https://doi.org/10.1021/acs.analchem.5b01761.

Njagi J, Chernov MM, Leiter JC, Andreescu S. Amperometric detection of dopamine in vivo with an enzyme based carbon fiber microbiosensor. Anal Chem. 2010;82(3):989-96. https://doi.org/10.1021/ac9022605.

Rabti A, Raouafi N, Merkoçi A. Bio(Sensing) devices based on ferrocenefunctionalized graphene and carbon nanotubes. Carbon. 2016;108:481-514 https://doi.org/10.1016/j.carbon.2016.07.043.

Schultz W. Dopamine neurons and their role in reward mechanisms. Curr Opin Neurol. 1997;7(2):191-7. https://doi.org/10.1016/S0959-4388(97)80007-4.

Seenivasan R, Chang WJ, Gunasekaran S. Highly sensitive detection and removal of lead ions in water using cysteine-functionalized graphene oxide/ polypyrrole nanocomposite film electrode. ACS Appl Mater Interfaces. 2015; 7(29):15935-43. https://doi.org/10.1021/acsami.5b03904.

Si P, Chen H, Kannan P, Kim DH. Selective and sensitive determination of dopamine by composites of polypyrrole and graphene modified electrodes. Analyst. 2011;136(24):5134-8. https://doi.org/10.1039/c1an15772h.

Sun Y, He K, Zhang Z, Zhou A, Duan H. Real-time electrochemical detection of hydrogen peroxide secretion in live cells by Pt nanoparticles decorated graphene-carbon nanotube hybrid paper electrode. Biosens Bioelectron. 2015;68:358-64. https://doi.org/10.1016/j.bios.2015.01.017.

Tan C, Zhang W, Zheng J, You X, Lin X, Li S. Fabrication of metal-organic single crystalline nanowires and reduced graphene oxide enhancement for an ultrasensitive electrochemical biosensor. J Mater Chem B. 2015;3(35):7117-24. https://doi.org/10.1039/c5tb01199j.

Tang L, Du D, Yang F, Liang Z, Ning Y, Wang H, Zhang GJ. Preparation of graphene-modified acupuncture needle and its application in detecting neurotransmitters. Sci Rep. 2015;5:11627. https://doi.org/10.1038/srep11627.

Thirumalraj B, Palanisamy S, Chen SM, Lou BS. Preparation of highly stable fullerene C60 decorated graphene oxide nanocomposite and its sensitive electrochemical detection of dopamine in rat brain and pharmaceutical samples. J Colloid Interface Sci. 2016;462:375-81. https://doi.org/10.1016/j.jcis. 2015.10.009.

Thirumalraj B, Rajkumar C, Chen SM, Palanisamy S. One-pot green synthesis of graphene nanosheets encapsulated gold nanoparticles for sensitive and selective detection of dopamine. Sci Rep. 2017;7:41213. https://doi.org/10. 1038/srep41213. 
Vellaichamy B, Periakaruppan P, Paulmony T. Evaluation of a new biosensor based on in situ synthesized PPy-Ag-PVP nanohybrid for selective detection of dopamine. J Phys Chem B. 2017;121(5):1118-27. https://doi.org/10.1021/ acs.jpcb.6b11225.

Vinayan BP, Nagar R, Raman V, Rajalakshmi N, Dhathathreyan KS, Ramaprabhu S. Synthesis of graphene-multiwalled carbon nanotubes hybrid nanostructure by strengthened electrostatic interaction and its lithium ion battery application. J Mater Chem. 2012;22(19):9949-56. https://doi.org/10.1039/ c2jm16294f.

Wang W, Xu G, Cui XT, Sheng G, Luo X. Enhanced catalytic and dopamine sensing properties of electrochemically reduced conducting polymer nanocomposite doped with pure graphene oxide. Biosens Bioelectron. 2014; 58:153-6. https://doi.org/10.1016/j.bios.2014.02.055.

Wei W, Wang G, Yang S, Feng X, Mullen K. Efficient coupling of nanoparticles to electrochemically exfoliated graphene. J Am Chem Soc. 2015:137(16):557681. https://doi.org/10.1021/jacs.5b02284.

Woo S, Kim YR, Chung TD, Piao Y, Kim H. Synthesis of a graphene-carbon nanotube composite and its electrochemical sensing of hydrogen peroxide. Electrochim Acta. 2012;59:509-14. https://doi.org/10.1016/j.electacta.2011.11.012.

Yang L, Yang J, Xu B, Zhao F, Zeng B. Facile preparation of molecularly imprinted polypyrrole-graphene-multiwalled carbon nanotubes composite film modified electrode for rutin sensing. Talanta. 2016;161:413-8. https://doi.org/ 10.1016/j.talanta.2016.08.080

Zhang W, Zheng J, Shi J, Lin Z, Huang Q, Zhang H, Wei C, Chen J, Hu S, Hao A. Nafion covered core-shell structured $\mathrm{Fe}_{3} \mathrm{O}_{4} @$ graphene nanospheres modified electrode for highly selective detection of dopamine. Anal Chim Acta. 2015, 853:285-90. https://doi.org/10.1016/j.aca.2014.10.032.

\section{Publisher's Note}

Springer Nature remains neutral with regard to jurisdictional claims in published maps and institutional affiliations.

\section{Submit your manuscript to a SpringerOpen ${ }^{\circ}$ journal and benefit from:}

- Convenient online submission

- Rigorous peer review

- Open access: articles freely available online

- High visibility within the field

- Retaining the copyright to your article

Submit your next manuscript at $\boldsymbol{\nabla}$ springeropen.com 